\title{
EL (DES) EMPLEO RECIENTE EN MÉXICO, SU PERSPECTIVA Y SUS REQUERIMIENTOS FINANCIEROS
}

\author{
Ernesto Peralta Solorio* \\ Departamento de Economía \\ El Colegio de la Frontera Norte A.C.
}

(Recibido 10 de octubre 2005, aceptado 21 de diciembre 2005)

\section{Resumen}

Se proyecta la perspectiva laboral por confrontar los empleos requeridos dados por la futura población económicamente activa (oferta) con los estimados a través de diferentes escenarios de empleo permanente (demanda), para el periodo 2005-2015; los escenarios combinan crecimiento y estructura económicos a través del Producto Interno Bruto; como importante corolario se derivan sus requerimientos financieros con base en las razones capital/producto, capital/trabajo y los empleos formales por crear, estimados con estadísticas confiables y en parámetros internacionales. Se infiere la dificultad de satisfacer los empleos requeridos, pero se trazan perspectivas realistas.

\section{Abstract}

The labor perspective projects to confront the required employments given by the future economically active population (supply) with the considered ones through different scenes from permanent employment (demand), for period 2005-2015; the scenes combine economic growth and structure through the Gross Internal Product; as important corolario their financial requirements with base in the reasons capital/product and capital/work are derived and the formal emploement to create, considered with reliable statistics and international parameters. The difficulty is inferred to satisfy the required employment, but realistic perspective draw up.

Clasificación JEL: J33, J64

Palabras clave: (Des)empleo, Escenarios, Financiamiento

* El Colegio de la Frontera Norte A.C., Subsede Noreste-Monterrey. Técnicos no. 277, esquina Río Pánuco, Col. Tecnológico, Monterrey, Nuevo León. C.P. 64700. México. Teléfono +52 (55) 8358-6401. Correo electrónico: efperaita@terra.com.mx 


\section{Introducción}

Este artículo analiza el (des)empleo ${ }^{1}$ en México entre los años 1993 y 2004, lo visualiza al 2015 y propone pautas a la política contra el desempleo, pues en ese horizonte se podrían instrumentar recomendaciones como las aquí sugeridas y, muy importante, para el cual los futuros buscadores de trabajo ya existen. De esa perspectiva se desprenden los requerimientos financieros para que la economía crezca y genere empleos, estimados en pesos y como parte del Producto Interno Bruto (PIB) bajo diferentes escenarios.

La hipótesis estriba en que es imposible abatir el desempleo, pero se le puede reducir mediante un mayor crecimiento y la restructuración económicos, soportados en recursos financieros cuyas dimensiones aquí se dan.

Si se entiende qué es, cómo se compone y a dónde iría el (des)empleo, con apoyo del marco teórico apropiado, se tendrá una referencia y otra advertencia sobre la retadora perspectiva de crear empleos suficientes y decorosos; advertencia como aquéllas cuya prospectiva iba a fin del siglo $\mathrm{XX} ;{ }^{2}$ pero no se les consideró, y el desempleo se desbordó; ojalá ahora tengamos mejor suerte.

Como todo mercado, el de trabajo implica oferta y demanda; y aquí la primera es la Población Económicamente Activa (PEA), que el Instituto Nacional de Estadística, Geografía e Informática (INEGI) considera:

Son todas las personas de 12 años y más que en la semana de referencia realizaron algún tipo de actividad económica, o formaban parte de la población desocupada abierta. ${ }^{3}$

Y de la cual ya se tiene mejor información en la Encuesta Nacional de Empleo (la Encuesta, en adelante) que el INEGI publica anualmente desde $1993{ }^{4}$ pues supera las limitaciones de los censos de población, cuyas cambiantes definiciones y errores a veces los hicieron poco confiables; amplía la cobertura de los censos económicos, que omiten la rama agropecuaria y al sector informal; y supera a la Encuesta Nacional de Empleo Urbano, pues como su nombre dice, se enfoca a zonas urbanas pero no todas ni siempre las más importantes. Y la demanda sería el empleo permanente, formal o decente, según la Organización Internacional del Trabajo (OIT), como se explica líneas abajo. El artículo tiene seis secciones: 1. El marco conceptual y teórico; 2. La evolución reciente del (des)empleo; 3.

1 El Instituto Nacional de Estadística Geografía e Informática (INEGI, 2001) toma como sinónimos los términos desempleado y desocupado, y así en este trabajo; ver sus publicaciones sobre empleo y desempleo, por ejemplo, el XII Censo General de Población y Vivienda Tomo II, Aguascalientes, p. 1071.

2 Víctor Urquidi (1974), Empleo y explosión demográfica. Demografía y Economía, El Colegio de México, México, Vol. VIII, num. 2, pp. 141-153. Sofía Méndez Villarreal (14 de mayo de 1975), Urgen 800 mil nuevos empleos. Revista Siempre, p. 19. Francisco Alba (1984), Logros y limitaciones en la absorción de la fuerza de trabajo en México. Demografía y Economía, El Colegio de México, Vol. XVIII; NUM. 4, pp. 557-580. Saúl Trejo Reyes 1988), Empleo para todos. El reto y los caminos, Fondo de Cultura Económica, 200 páginas.

3 INEGI (2005), Encuesta Nacional de Empleo 2004, Aguascalientes, p. 162.

4 Excepto para 1994. 
La (in)formalidad del empleo; 4. Perspectiva 2000-2015; 5. Los requerimientos financieros y 6 . Conclusiones.

\subsection{Marco conceptual y teórico.}

Primero aclaremos tres conceptos aquí usados: i) el desempleo es no utilización de trabajo ${ }^{5}$ y no sólo desempleo abierto; ii) se toma como referencia al empleo decente, que según la OIT, es:

un trabajo productivo con una remuneración justa, seguridad en el lugar de trabajo y protección social para las familias, mejores perspectivas para el desarrollo personal y la integración social. ${ }^{6}$

Por ende, iii) el empleo informal, contraparte del empleo decente, es el que incluye a los ocupados que:

Carecen de un contrato de trabajo y cobertura en la seguridad social. ${ }^{7}$

Y aunque la seguridad social caracterice a la formalidad, aquí se toma como ocupación informal aquélla sin prestaciones, cuya primera estimación se ve en el Cuadro 1; si se adopta sólo la de seguridad social, la informalildad pasaría de 62.6 (Cuadro 1) a 66.8 porciento de la PEA ocupada (u ocupación), pues hay ocupados sin seguridad social con prestaciones que mejoran calidad y remuneración de su empleo.

Cuadro 1. La informalidad del empleo por ramas de actividad en en México, 2004.

\begin{tabular}{|l|c|c|c|c|}
\hline Rama de actividad & $\begin{array}{c}\text { Total de } \\
\text { ocupados } \\
(1)\end{array}$ & $\begin{array}{c}\text { Ocupados sin } \\
\text { prestaciones } \\
(2)\end{array}$ & $\begin{array}{c}\text { \% informal } \\
\text { por rama } \\
(3)=(2) /(1)\end{array}$ & $\begin{array}{c}\text { Estruc. } \\
\text { informal } \\
\%\end{array}$ \\
\hline 1. Actividades agropecuarias & $6,937,881$ & $6,510,398$ & 93.8 & 24.6 \\
2. Extractivas, de transfor- & & & & \\
mación y electricidad & $7,759,866$ & $3,207,00841.3$ & 41.3 & 12.1 \\
3. Construcción & $2,741,769$ & $2,194,803$ & 80.1 & 8.3 \\
4. Comercio & $8,147,672$ & $5,897,595$ & 72.4 & 22.3 \\
5. Comunicaciones y trans- & & & & \\
portes & $1,888,703$ & $1,164,284$ & 61.6 & 4.4 \\
6. Administración pública & & & & 0.6 \\
y defensa & $1,816,169$ & 159,189 & 8.8 & \\
\hline
\end{tabular}

5 The Harper Collins Dictionary ECONOMICS (1991), p. 533.

6 Organización Internacional del Trabajo http://www.ilo.org/public/spanish/decen.htm (consulta en junio de 2005)

7 INEGI (2004), La ocupación en el sector no estructurado en México 1995-2003, México, 171 páginas, en donde se presentan (página vii) los térninos informal y no estructurado como sinónimos. 
Cuadro 1. (continuación).

\begin{tabular}{|l|c|c|c|c|}
\hline Rama de actividad & $\begin{array}{c}\text { Total de } \\
\text { ocupados } \\
(1)\end{array}$ & $\begin{array}{c}\text { Ocupados sin } \\
\text { prestaciones } \\
(2)\end{array}$ & $\begin{array}{c}\% \text { informal } \\
\text { por rama } \\
(3)=(2) /(1)\end{array}$ & $\begin{array}{c}\text { Estruc. } \\
\text { informal } \\
\%\end{array}$ \\
\hline 7. Servicios financieros, & & & & \\
profesionales y sociales & $5,715,967$ & $1,718,548$ & 30.1 & 6.5 \\
8. Servicios personales & $7,135,500$ & $5,505,254$ & 77.2 & 20.8 \\
9. No especificado & 162,536 & 111,202 & 68.4 & 0.4 \\
\hline Total o promedio & $42,306,063$ & $26,468,281$ & 62.6 & 100.0 \\
\hline
\end{tabular}

* Fuente: Construido con datos del INEGI. Encuesta Nacional de Empleo, 2004. pág. 90.

Y se toma al empleo permanente, del Instituto Mexicano del Seguro Social (IMSS), por su información accesible. ${ }^{8}$ Así, se presenta primero la ocupación en su marco poblacional en el Gráfico 1, donde se ve que: i) el empleo formal es porción pequeña de una PEA inferior a la mitad de la población total; ii) la tendencia y magnitud de la ocupación remunerada siguen de cerca a la PEA ocupada; y iii) el desempleo abierto apenas se distingue: pequeña distancia entre las líneas de PEA y PEA ocupada. Y antes de analizar estas tendencias y niveles, se les ubica en un marco teórico que se juzgó apropiado por las razones que ahora se indican.

Gráfico 1. Población y ocupación en México, 1993-2004.

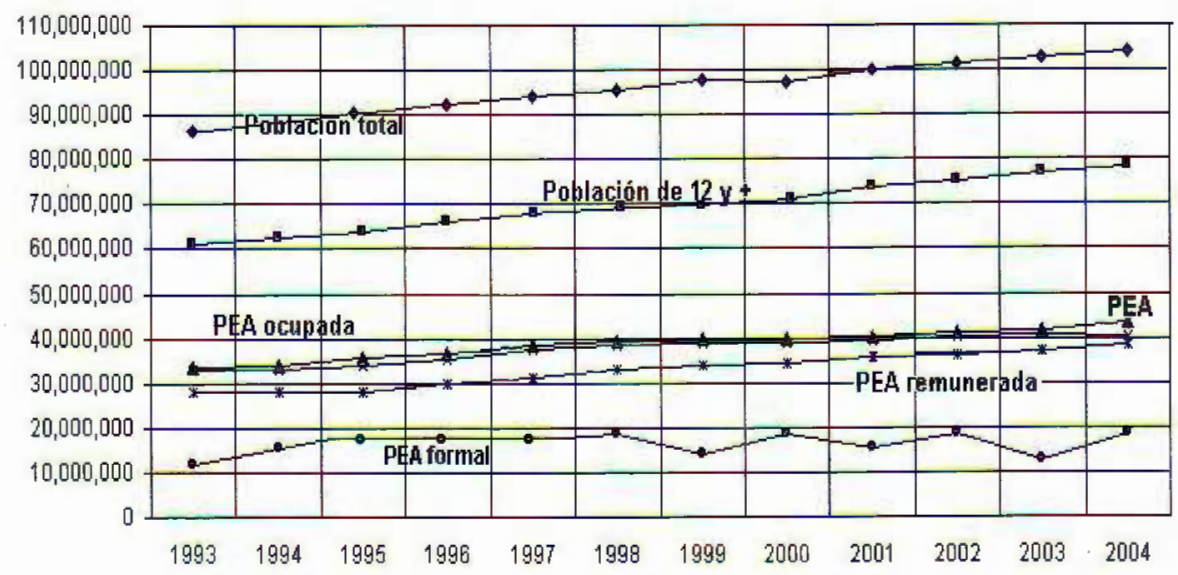

* Fuente: construido con datos de INEGI, Encuesta Nacional de Empleo.

8 El IMSS es la única fuente oficial de empleo permanente que publica datos mensuales, incluso por ramas de actividad y entidad federativa. 


\subsection{El marco teórico}

Se adoptó un viejo modelo que permite evaluar el (des)empleo en un país como México, el de Ranis y Fei (RyF) ${ }^{9}$ nacido de la tradición clásica de Smith a Lewis. ${ }^{10}$ Se le adoptó porque:

a) supone una oferta ilimitada de trabajo (los neoclásicos la suponen escasa) nutrida en: i) el crecimiento demográfico, ii) la participación laboral femenina, iii) la emigración laboral del sector tradicional al moderno y iv) el desempleo generado por la innovación; fuentes bien presentes en México, pues entre los años 1993 y 2004: i) la tasa anual de crecimiento demográfico fue $1.7 \%$, mayor a la media mundial y triple que la de EE. UU.(la de la PEA mexicana fue $2.3 \%$ ); ii) la proporción de PEA femenina pasó de 31 a 36 ; iii) el porciento de empleo informal (sin prestaciones) oscila entre 43 y 69 , con tendencia creciente ${ }^{11}$ y iv) el desplazamiento laboral por la tecnología se entrevé en la industria de transformación, donde pasó de 3,655 (miles de trabajadores) a 3,665 entre los años 1997 y 2003, práctico estancamiento, pero su PIB creció $15.7 \%{ }^{12}$

b) como escribe Joseph Stiglitz:

Desde Keynes y la Gran Depresión, pocos han creído en la ley de Say, según la cual un aumento de la oferta de mano de obra se traduce automáticamente en un aumento de la demanda. ${ }^{13}$

Si se concuerda con Stiglitz, se soslayaría la visión neoclásica, que margina la intervención estatal, ve al trabajo como insumo y entroniza la libertad de mercado (de capitales), pero no siempre al empleo como aspecto humano; ${ }^{14}$

c) La aplicación reciente del modelo neoclásico de Solow - muy difundido - no acaba de explicar el crecimiento en los países pobres; ${ }^{15}$

d) el modelo RyF toma al empleo como fenómeno explicado; el de Solow, como explicativo.

9 Ranis, Gustav and John Fei (September, 1961). A theory of economic development. American Economic Review, pp. 533-565.

10 El trabajo básico es el de Arthur Lewis, pero RyF lo precisan. El modelo de Lewis aparece en Economic development with unlimited supplies of labor, The Manchester School (mayo, 1954); su versión en Español es la de Agarwala y Sing (1963), El desarrollo económico con oferta ilimitada de trabajo. La economía del subdesarrollo, Tecnos, Madrid, pp. 333-374; y es la referencia aquí usada.

11 La línea de regresión \% Ocupación iñformal $=52.4+.59$ tiempo, en años.

12 Los datos de población y PEA son de la Encuesta; el de crecimiento demográfico de EE. UU., de la página Internet del U. S. Census Bureau; los de la industria manufacturera, según el INEGI (página internet).

13 Joseph Stiglitz (2002), Empleo, justicia social y bienestar de la sociedad. Revista Internacional del Trabajo, Vol. 121. Número 1-2, Oficina Internacional del Trabajo (OIT), Ginebra, p. 17.

14 Stiglitz, op. Cit., pp. 10-14.

15 Charles Jones (2000), Introducción al crecimiento económico, Prentice Hall, México, pp. 32-77. 
e) por último, la política económica mexicana desde los años ochenta parece basarse en lo neoclásico, pues prioriza bajar la inflación pero margina crecimiento y empleo; la tasa de crecimiento del PIB per capita fue $0.5 \%$ entre 1982 y 2004 que de continuar, duplicarlo llevaría 140 años; y por el lado del trabajo, entre los años 1993 y 2004, la PEA creció diez millones mientras que el empleo permanente, sólo seis.

\section{Gráfico 2. El modelo de Ranis \& Fei}

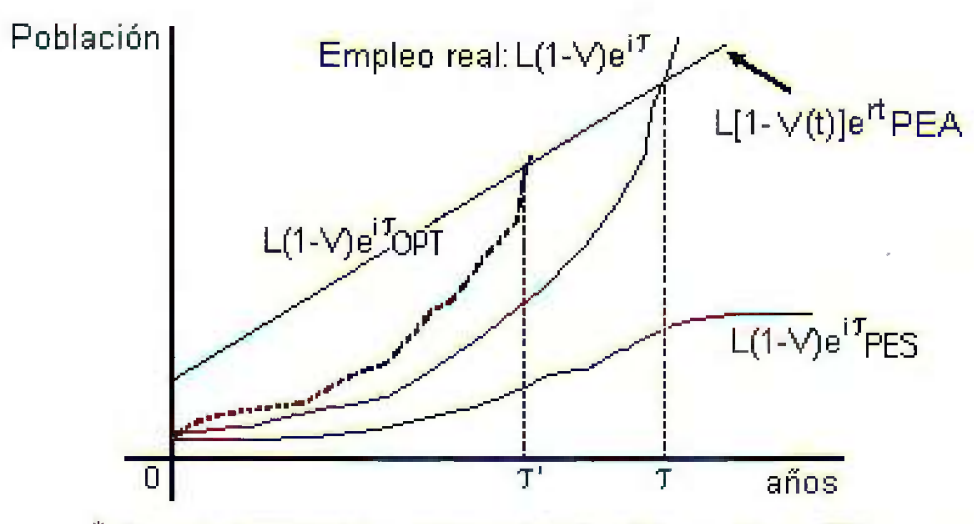

* Fuente: tomado del modelo de Ranis y Fei, op cit., p. 551

El modelo se resume en el Gráfico 2, donde la oferta labora es la recta $L[1$ $V(t)] e^{r t}$ PEA, pero el empleo - demanda - se ve de dos modos: i) el pesimista, según la línea $L(1-V) e^{i \tau} \mathrm{PES}$, que no elimina el desempleo, dado por la distancia entre esas dos líneas; y ii) el optimista, cuando el empleo con la curva $L(1-V) e^{i \tau}$ OPT que alcanza la de oferta laboral $L[1-V(t)] e^{r t} \mathrm{PEA}$ en la fecha $\tau^{\prime}$ : elimina el desempleo. RyF recomiendan aumentar la inversión y cambiar su estructura para que el empleo crezca a la tasa $i$, mayor que $r$, ésta la de crecimiento de la PEA; pues si $i \leq r$, se cae en el escenario pesimista; $i$ viene a ser el esfuerzo nacional:

El esfuerzo nacional en i es así una función del monto absoluto del fondo de inversión que puede estar disponible cada año durante el curso del proceso de despegue y un función de la eficiencia de su uso en los dos sectores. Una i mayor significa una tasa anual más acelerada de absorción de mano de obra por el sector industrial; pero esto, debe recalcarse, necesita también de una mayor tasa de inversión en el sector agrícola, para alimentar a la creciente población, y una mayor tasa de inversión en el sector industrial, para absorber a la fuerza de trabajo agrícola lilberada, con asignaciones entre los dos sectores obedeciendo nuestro criterio de crecimiento balanceado. ${ }^{16}$

16 Ranis, Gustav and John Fei, Op. Cit. p. 353. Nota: a los sectores industrial y agrícola, RyF les llaman moderno y tradicional, y así en este artículo. 
Así, para promover el crecimiento económico y el empleo, se precisa de mayor inversión y de atender a su distribución sectorial.

\section{Evolución reciente del (des)empleo}

En el Gráfico 1 se vio que la PEA y la población en edad laboral (de doce y más años) ${ }^{17}$ avanzan más rápido que la población total, ya la de doce y más representó 70.4 porciento en 1993 y para el 2004, 75.1: un modo de ver el envejecimiento; la PEA también gana importancia demográfica entre 1993 y 2004 , de 38.9 a 40.7 porciento, porciento llamado tasa bruta de actividad cuyo complemento a 100 (sendos 61.1 y 59.3) indica cuántas personas serían dependientes, dependencia alterada por el número de desocupados, lo que obliga un ajuste para considerar sólo la PEA ocupada, mas como se ve en el Gráfico 1, las líneas de ésta y la de PEA en poco se separan, pequeña diferencia que da el desempleo abierto cuyo máximo fue 4.7 porciento de la PEA en el año crítico de $1995 ;^{18}$ pequeño porque las personas difícilmente se quedan inactivas al carecer de apoyos (como seguro contra desempleo), máxime si enfrentan obligaciones familiares; incluso se (auto)emplean en actividades marginales, como la de vendedor ambulante; conviene entonces estimar el desempleo de modo más realista, como se propone líneas adelante, y como ya lo hace el INEGI porque además de la tasa de desempleo abierto (tda) aporta otras diez donde la máxima suma desocupados y los que laboran menos de 35 horas por semana (Tasa de ocupación parcial y desocupación: TOPD2), que exagera el desempleo al incluir personas que trabajan menos de 35 horas, cierto, pero es la jornada que ofrecen, y por ende no se les puede considerar desocupados necesariamente. Por esto, desde 1974 Altimir $^{19}$ veía como dato más confiable de empleo el de PEA remunerada, cuyas tendencias se ven en el Gráfico 1; la distancia entre ellas se debe a los trabajadores sin pago principalmente, la mayoría en negocios familiares. La estructura ocupacional por ramas se ve en el Gráfico 3, donde la agropecuaria, industria de transformación, comercio y servicios personales absorben más de 80 porciento de la ocupación; se ve que la agropecuaria capta un porción decreciente y los servicios, una creciente. Pero el PIB tiene otra distribución, Gráfico 4, que es la otra referencia para estimar la productividad; las ramas de mayor empleo (agropecuaria y servicios) tienen menos peso en el PIB, y son de baja productividad relativa, ${ }^{20}$ menor a 1 , respecto a la media nacional; para percibir su evolución se hizo el Cuadro 2 con cifras de los años extremos con información disponible (la de 2003 y 2004 no se publicó), donde se ve que esas ramas son las menos productivas y que la productividad general bajó: el PIB creció menos que la ocupación.

17 Límite tomado por el INEGI (2005), Encuesta Nacional de Empleo 2004, Aguascalientes, p. 162.

18 Bajo la más severa crisis desde 1932 según el Banco de México, The Mexican Economy 1996, México, p. 1; la tasa de desempleo mexicana es pequeña cuando se compara con las de Estados Unidos, Alemania y Argentina: 5.6, 12.9 y 17.5 por ciento respectivamente, en 1995, según página Internet de la OIT.

19 Altimir Oscar (1974), La medición de la población económicamente activa en México, 1950-1970: Demografía y Economía, Vol. VIII. Num, 1, El Colegio de México, pp. 69-70.

20 Cuya media estandarizada es uno: 100 del PIB/100 de la ocupación $=1$. 
Cuadro 2. Estructura productiva y de ocupación: razón de productividad relativa.

\begin{tabular}{|l|c|c|c|c|c|c|}
\hline Rama de Actividad & 1993 & 2002 & 1993 & 2002 & 1993 & 2002 \\
\hline & \multicolumn{3}{|c|}{ PIB } & \multicolumn{2}{|c|}{$/$ Ocupación } & \multicolumn{2}{|c|}{ Productividad } \\
\hline 1. Actuvidad agropecuarias & 6,1 & 5,5 & 27,1 & 17,9 & 0,23 & 0,31 \\
2. Industria extractiva & 1,4 & 1,3 & 0,5 & 0,5 & 2,61 & 2,32 \\
3. Industria de transformación & 18,5 & 19,7 & 15,6 & 17,6 & 1,19 & 1,12 \\
4. Electricidad & 1,5 & 1,8 & 0,3 & 0,5 & 5,07 & 3,57 \\
5. Construcción & 4,7 & 3,9 & 5,8 & 6,3 & 0,81 & 0,63 \\
6. Comercio & 21,2 & 20,7 & 17,2 & 18,6 & 1,23 & 1,12 \\
7. Comunicaciones y Transporte & 9,0 & 11,4 & 4,2 & 4,6 & 2,16 & 2,50 \\
8. Servicios & 15,4 & 16,3 & 25,4 & 29,5 & 0,61 & 0,55 \\
9. Administración Pública & & & & & & \\
y defensa & 22,2 & 19,3 & 3,9 & 4,5 & 5,64 & 4,30 \\
\hline Estruc. y productividad relativa & 100,0 & 100,0 & 100,0 & 100,0 & 1,00 & 1,00 \\
\hline
\end{tabular}

* Fuente: construido con datos de INEGI, Encuesta Nacional de Empleo 1993 y 2002.

Gráfico 3. Estructura ocupacional por sectores, 1993-2004.

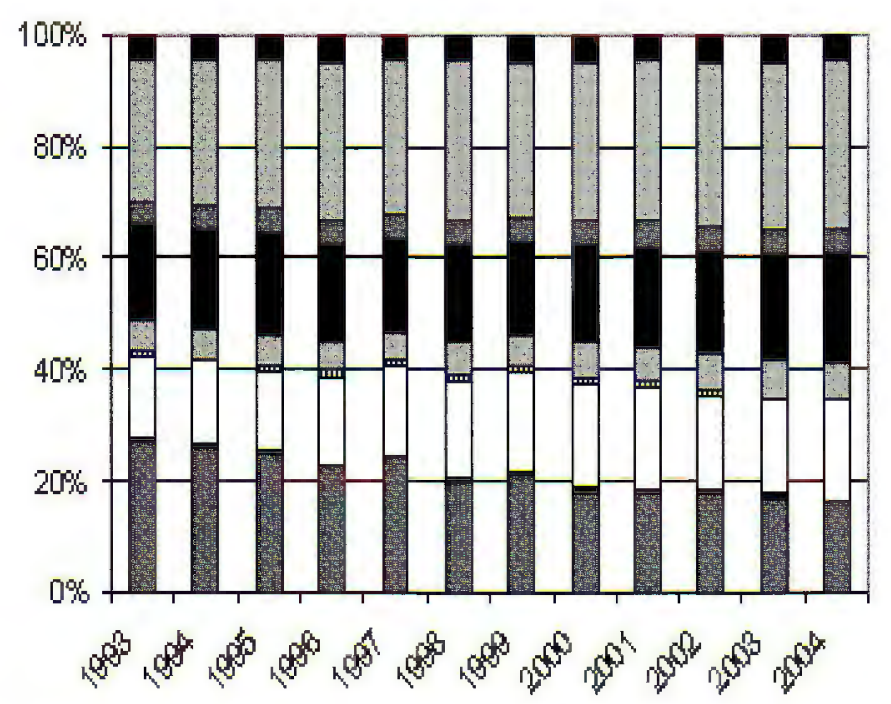

10. Ho especificado

9. Admom Fúb lica y Defensa

圆8.Semicios

0 7. Com y Trang p.

6. Comercio

5.Constueción

II 4. Elentricidad

प3. Indust. de transfommión

-2. Ird. extactiva

1. Actividade agropecuarias

* Fuente: Con datos de INEGI, Encuesta Nacional de Empleo. 
Gráfico 4. Estructura del PIB por rama de activida, 1993-2004.

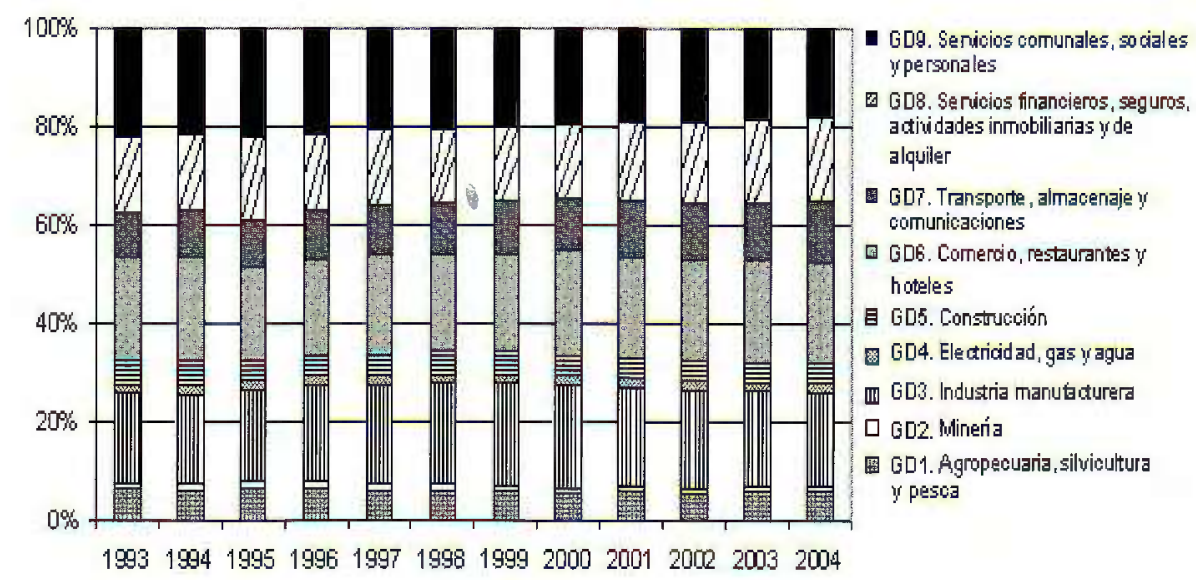

* Fuente: Con datos de INEGI, Encuesta Nacional de Empleo.

Como se sabe, la productividad de un factor es la base de su remuneración y si aquélla baja, ésta también; lo que no siempre muestran las estadísticas al ocultar desviaciones productivas y distributivas; pero buscando obviar esto, se hizo el Cuadro 3, empero, la información implica dos grupos confusos: i) el de ocupados con ingresos superiores a diez salarios minimos (SM), sin límite, y ii) el no especificados, ambos con estadísticos desconocidos que de saberse ayudarían a visualizar la distribución del ingreso; pero el salario mínimo real baja y la mediana sube, lo que implicaría menor concentración, a juzgar por la declinación del Coeficiente de Gini. ${ }^{21}$

Cuadro 3. Salario mínimo y mediana de ingreso diario de la PEA ocupada, 1993-2004.

\begin{tabular}{|c|c|c|c|}
\hline Año & $\begin{array}{c}\text { Salario mínimo diario en } \\
\text { pesos del año 2002 }\end{array}$ & $\begin{array}{c}\text { Mediana de ingreso } \\
\text { diario en pesos del 2002 }\end{array}$ & $\begin{array}{c}\text { Coeficiente } \\
\text { de Gini }\end{array}$ \\
\hline 1993 & 51.0 & 52.5 & .53 \\
1994 & 50.3 & $\mathrm{Nd}$ & $\mathrm{Nd}$ \\
1995 & 40.0 & 37.8 & .55 \\
1996 & 36.6 & 34.8 & .54 \\
1997 & 40.1 & 36.6 & .55 \\
1998 & 39.8 & 40.1 & .54 \\
1999 & 39.0 & 41.1 & .52 \\
2000 & 39.1 & 49.6 & .52 \\
\hline
\end{tabular}

21 Para estimar el Coeficiente de Gini se tomó el límite superior por seguir la línea de tendencia ingreso -ocupación según la Encuesta - que resulta una exponencial, y el límite superior se fijó en 15 salarios mínimos. Respecto a la tendencia del CG contra el tiempo, la ecuación resultante fue $\mathrm{CG}=0.5518-.0041$ tiempo. 
Cuadro 3. (continuación).

\begin{tabular}{|c|c|c|c|}
\hline Año & $\begin{array}{c}\text { Salario mínimo diario en } \\
\text { pesos del año 2002 }\end{array}$ & $\begin{array}{c}\text { Mediana de ingreso } \\
\text { diario en pesos del 2002 }\end{array}$ & $\begin{array}{c}\text { Coeficiente } \\
\text { de Gini }\end{array}$ \\
\hline 2001 & 39.4 & 52.0 & .50 \\
2002 & 39.7 & 58.2 & .49 \\
2003 & 39.6 & 59.2 & .49 \\
2004 & 39.5 & 61.2 & .53 \\
\hline
\end{tabular}

* Fuente: el salario mínimo se ajustó con el Índice Nacional de Precios al Consumidor, de la página Internet del INEGI. La mediana se estimó de la tabla Población Ocupada-Nivel de Ingresos, de la Encuesta Nacional de Empleo.

Para incursionar en la distribución se hizo el Cuadro 4, que presenta datos de posición en el trabajo del año 2004, donde se ve que la mayoría recibe de uno a cinco SM, principalmente (61\%) compuesta por: i) asalariados, ii) por su cuenta y iii) a destajo. Quienes reciben más de diez SM representan $2.8 \%$, los del grupo no especificado $4.5 \%$, y los del sin pago $8.5 \%$. Pero una mediana de $\$ 61.2$ (última línea, Cuadro 3), no da para vivir bien, implica pobreza, tema muy atendido por investigadores personales e institucionales. ${ }^{22}$

Cuadro 4. La PEA ocupada por posición en el trabajo según ingreso en Salarios Mínimos, 2004.

\begin{tabular}{|c|c|c|c|c|c|c|}
\hline & \multicolumn{7}{|c|}{ Ingreso percibido (SM) } \\
\hline $\begin{array}{c}\text { Posición en } \\
\text { el trabajo }\end{array}$ & $\begin{array}{c}\text { Mas de } \\
10 \mathrm{SM}\end{array}$ & $\begin{array}{c}\text { Mas de } \\
5 \mathrm{a} 10\end{array}$ & $\begin{array}{c}\text { Mas de } \\
3 \mathrm{a} 5\end{array}$ & $\begin{array}{c}\text { Mas de } \\
2 \mathrm{a} 3\end{array}$ & $\begin{array}{c}\text { De 1 a } \\
2\end{array}$ & $\begin{array}{c}\text { Menos } \\
\text { que 1 }\end{array}$ \\
\hline Empleadores & 0.62 & 0.96 & 0.98 & 0.55 & 0.37 & 0.29 \\
\hline Por su cuenta & 0.38 & 1.46 & 3.34 & 3.28 & 5.44 & 9.64 \\
\hline Asalariado & 1.67 & 5.15 & 11.29 & 16.03 & 15.38 & 4.41 \\
\hline A destajo & 0.10 & 0.48 & 1.16 & 1.38 & 1.53 & 1.12 \\
\hline $\begin{array}{c}\text { Familiares } \\
\text { sin pago }\end{array}$ & 0.00 & 0.00 & 0.00 & 0.00 & 0.00 & 0.00 \\
\hline $\begin{array}{c}\text { No Familiares } \\
\text { sin pago }\end{array}$ & 0.00 & 0.00 & 0.00 & 0.00 & 0.00 & 0.00 \\
\hline Otros & 0.00 & 0.00 & 0.01 & 0.01 & 0.01 & 0.00 \\
\hline Suma & 2.77 & 8.05 & 16.78 & 21.24 & 22.74 & 15.46 \\
\hline
\end{tabular}

22 Como la del Banco Mundial (2001), Labor markets. Mexico. A Comprehensive Development Agenda for the New Era. The World Bank, Washington, D.C., pp. 511-536. 
Cuadro 4. (continuación).

\begin{tabular}{|c|c|c|c|}
\hline & \multicolumn{3}{|c|}{ Ingreso percibido (SM) } \\
\hline $\begin{array}{c}\text { Posición en } \\
\text { eltrabajo }\end{array}$ & $\begin{array}{c}\text { No recibe } \\
\text { ingresos }\end{array}$ & ne & Suma \\
\hline Emple. & 0.00 & 0.46 & 4.23 \\
\hline Por su cuenta & 0.00 & 1.29 & 24.83 \\
\hline Asalariado & 0.00 & 2.45 & 56.38 \\
\hline A destajo & 0.00 & 0.28 & 6.05 \\
\hline $\begin{array}{c}\text { Familiares } \\
\text { sin pago }\end{array}$ & 8.33 & 0.00 & 8.33 \\
\hline $\begin{array}{c}\text { No Familiares } \\
\text { sin pago }\end{array}$ & 0.16 & 0.00 & 0.16 \\
\hline Otros & 0.00 & 0.00 & 0.03 \\
\hline Suma & 8.48 & 4.48 & 100.00 \\
\hline
\end{tabular}

* Fuente: hecho con datos del INEGI, Encuesta Nacional de Empleo, Aguascalientes, 2005, p. 189. PEA ocupada $=100: 42,089,401$; ne, no especificado.

Si el exceso de oferta laboral es desempleo, la tasa de desempleo abierto (tda) lo subestima y la máxima que el INEGI reporta, TOPD2, lo sobrestima; pero si a ésta se la restan las personas que no se sienten desempleadas por trabajar menor de 35 horas por semana - es su jornada normal - se tiene una tasa (intermedia) más creible, que aquí se propone y muestra en el Gráfico 5, donde las tasas extremas del INEGI discrepan hasta en más de diez veces; se ve un leve ascenso de la tda luego del 2000 y otro menos leve de la intermedia desde 1997, cercana ya a la TOPD2 en el año 2004, atribuible a la decreciente proporción de personas que ven normal su jornada inferior a 35 horas.

Gráfico 5. Tasas de Desempleo, 1993-2004.

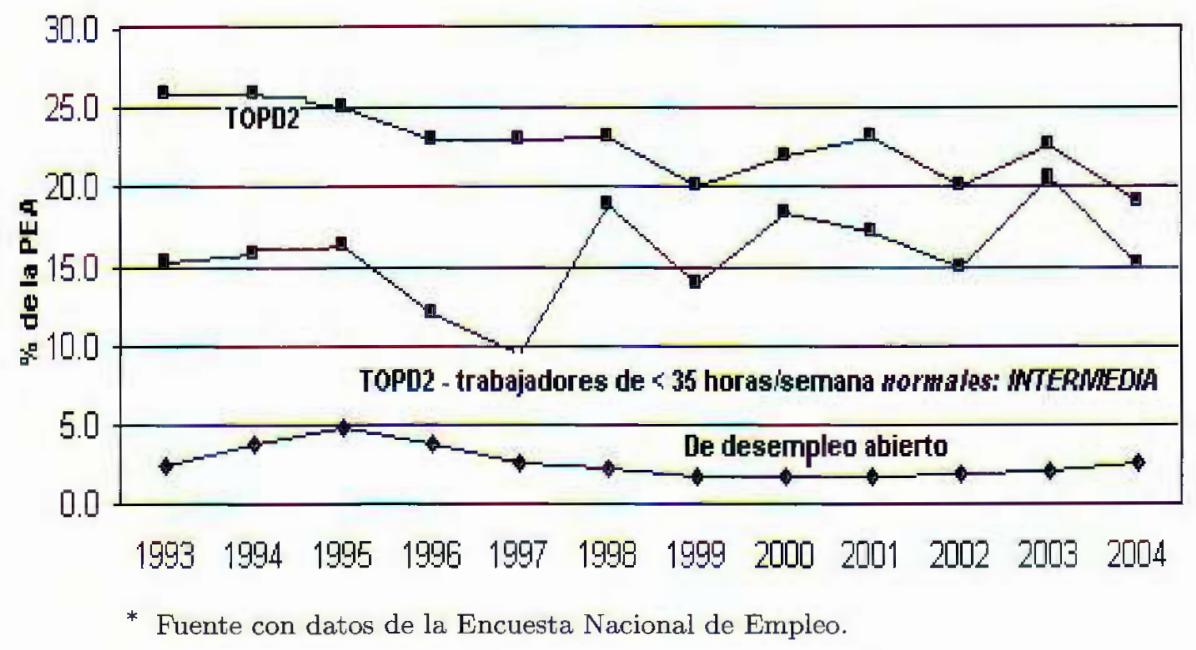


Y para abundar en el tema, se prueban dos conocidas proposiciones teóricas contra la evidencia:

i) El exceso de oferta sobre la demanda de un bien o servicio (aquí, trabajo) hace que su precio (salario) baje; relación inversa: a mayor desempleo, menor salario.

ii) La remuneración de un factor sube si sube su productividad; relación directa: a mayor productividad, mayor remuneración.

Entonces se estimaron los coeficientes de correlación entre remuneración y desempleo, y de remuneración con productividad, que se presentan en el Cuadro 5 y del cual se infiere que:

- Cuando se toma al salario mínimo (SM) hay aparentes contradicciones, pues el salario sube y el desempleo también, pero las correlaciones son bajas y no significativas; quizá explicable porque el salario mínimo no nace del mercado, sino que se fija institucionalmente, y sólo es una referencia.

- Con la mediana habría congruencia, excepto con la tasa intermedia y el porciento de PEA informal: a mayor desempleo o informalidad mayor mediana (ingreso), pero las $t$ implicarían no correlación; pero una parte del sector informal no siempre parece mal remunerador, y la mediana guarda cierta correlación $(\rho=0.56)$ con productividad; cabe decir que los ocupados sin pago disminuyeron entre 1993 y 2004, de 13.9 a 9.1 como porciento de la ocupación, y de 4.6 a 3.7 millones de personas, lo que habría promovido la masa salarial.

- El coeficiente de Gini (CG) mide la concentración del ingreso en la ocupación y va de 0 a 1: de distribución igualitaria a concentrada; se espera que a mayor desempleo mayor CG, y a mayor productividad general, menor CG; ambos casos se dan en el Cuadro 5, pero de nuevo las excepciones se dan con las tasas intermedia e informal, que implican una distribución menos desigual en el sector informal, algo congruente con el hecho de que la gente sin pago o de bajo ingreso haya mejorado su situación laboral (formal o informalmente), vía reducción de los ocupados sin pago, como se apuntó en el párrafo anterior y se vio en el Cuadro 3, donde el CG baja del máximo 0.55 en 1995, luego se cuasiestanca aunque con leve tendencia al alza, ${ }^{23}$ y queda 0.53 en el año 2004.

Cuadro 5. Coeficientes de correlación de remuneración con desempleo y productividad, 1993-2004.

\begin{tabular}{|c|c|c|c|}
\hline & tda & TOPD2 & $\begin{array}{c}\text { TOPD2-<35 } \\
\text { (intermedia) }\end{array}$ \\
\hline Salario Mínimo & 0.18 & 0.65 & 0.03 \\
\hline Valores t & 0.55 & 2.57 & 0.09 \\
\hline Mediana & -0.59 & -0.54 & 0.35 \\
\hline Valores t & -2.19 & -1.92 & 1.12 \\
\hline C. de Gini & 0.56 & 0.4 & -0.54 \\
\hline Valores t & 2.03 & 1.31 & -1.92 \\
\hline
\end{tabular}

23 Al ajustar el CG contra el tiempo, salió la ecuación $C G=0.5246+.0057 x$, donde $x$ es el tiempo medido en años. 
Cuadro 5.(continuación).

\begin{tabular}{|c|c|c|c|}
\hline & $\begin{array}{c}\text { \% PEA } \\
\text { informal }\end{array}$ & (PEA-PEArem)/PEA & $\begin{array}{c}\text { Productividad: } \\
\text { PIB/PEAocupada }\end{array}$ \\
\hline Salario Mínimo & 0.15 & 0.27 & 0.03 \\
\hline Valores t & 0.46 & 0.84 & 0.09 \\
\hline Mediana & 0.44 & -0.76 & 0.56 \\
\hline Valores t & 1.47 & -3.51 & 2.03 \\
\hline C. de Gini & -0.59 & 0.72 & -0.65 \\
\hline Valores t & -2.19 & 3.11 & -2.57 \\
\hline
\end{tabular}

* Fuente: el salario mínimo real se obtuvo por dividir el salario mínimo nominal entre el Índice Nacional de Precios al Consumidor, tomado de la página Internet del INEGI. Las tasas de desempleo, la mediana y el Coeficiente de Gini se estimaron con datos de la Encuesta; la productividad se obtuvo por dividir el PIB a precios de 1993 entre la PEA ocupada. Nota: en términos generales, si el valor t es menor a 2, el coeficiente no es estadísticamente significativo.

\section{La (in)formalidad del empleo}

El empleo informal aquí son los ocupados sin prestaciones; cuya importancia se mostró en el Cuadro 1: 62.6 porciento en el año 2004, mayor al reportado por la OIT para el sector urbano en 1999, 40.1; o respecto al del INEGI para el año 2000, 55.9; y mayor al de la Encuesta del sector no estructurado, también del INEGI en el año 2003: 33.7, pero omite las ramas Agropecuaria y de Administración pública y Defensa, la más informal y formal respectivamente. ${ }^{24}$ Se ratifica que en la agropecuaria, comercio y de servicios personales muchos se (auto)emplean, abundan los sin pago, a destajo, por su cuenta y asalariados de empresas pequeñas; informalidad que implica los tipos de desempleo cuya medición ahora se intenta.

\subsection{Tipos de Desempleo}

La PEA informal es área de desempleo mas no su indicador preciso; su desglose ayuda a medir los tres tipos tradicionales de desempleo: ${ }^{25}$

i) friccional, cuando la gente está cambiando de trabajo y hay desempleados por un corto tiempo, entre empleo y empleo.

24 El estimado de la OIT según su página internet; el 55.9\% del 2000, de INEGI e IMSS (2001), Encuesta Nacional de Empleo y Seguridad Social, Aguascalientes, p. 27; el 33.7\%, de INEGI, obtenido por dividir la ocupación del sector no estructurado del 2003 (INEGI, 2004), La ocupación en el sector no estructurado en México 1995-2003, Aguascalientes, p. 59) entre la respectiva ocupación según la Encuesta, sin Actividades Agropecuarias ni Administración Pública y Defensa, pues se excluyen en la referencia anterior entre ( ).L

25 Para los tipos de desempleo se siguió una referencia muy reciente: Paul Samuelson y William Nordhaus (2005), Economics, McGrawHill, New York, pp. 654-655; o la misma clasificación aparece en una referencia antigua: Bruce Kaufman (1991), The economics of Labor Markets, The Dryden Press, U.S.A., pp. 622-626. 
ii) cíclico, cuando la demanda económica agregada baja porque el gasto total y el producto total caen; por ende este desempleo sube virtualmente en todo lugar; $\mathrm{y}$

iii) estructural, por la inadecuación entre oferta y demanda de trabajadores, pues la demanda de un tipo de trabajo crece y la de otro tipo cae, y el mercado no los ajusta rápido.

Ahora se procura, con limitaciones desde la teoría,${ }^{26}$ estimarlos en primer acercamiento pero con datos recientes; los pasos seguidos se resumen en el Cuadro 6 y son los siguientes:

- Como el desempleo friccional nace del movimiento contínuo de empleadores y trabajadores, se le estimó por sumar las personas en desempleo abierto buscan empleo por menos de 14 semanas, pues el friccional es de corta duración; su tasa aparece en la línea 7.1. Para el periodo 1996-2002, declina hasta el año 2000 y repunta luego, como se ve en el Cuadro 7, quizá porque la economía poco creció en el periodo $2000-2004,{ }^{27}$ mas los buscadores de empleo llegan porque la población total y la PEA crecen.

Cuadro 6. Estimación de tipos de desempleo en el año 2004 (trabajadores y en \%).

\begin{tabular}{|l|r|}
\hline Concepto & Datos o tasas \\
\hline 1. PEA & $43,398,755$ \\
\hline 2. - PEA ocupada & $42,306,063$ \\
\hline 3. = PEA de desocupación abierta & $1,092,692$ \\
\hline 4. PEA Ocupada sin prestaciones & $26,468,281$ \\
\hline 5. Informal agropecuaria & $6,510,398$ \\
\hline 6. Sector informal industria-comercio-servicios & $19,957,883$ \\
\hline 6.1 Ocupados < 35 horas/semana & $8,239,431$ \\
\hline 6.2 Ocupados < 35 : jornada normal & $4,343,228$ \\
\hline 7. Tasas de desempleo (\% de PEA): & $1,6 \%$ \\
\hline 7.1 Desempleo friccional & $9,0 \%$ \\
\hline 7.2 Desempleo cíclico & $21,8 \%$ \\
\hline 7.3 Desempleo estructural & \\
\hline
\end{tabular}

* Fuente: construido con datos del INEGI, Encuesta Nacional de Empleo 2004; la PEA informal es la de sin prestaciones.

- La tasa de desempleo cíclico se ve en la línea 7.2, obtenida por sumar los que trabajan menos de 35 horas por razones de mercado y por razones personales; el criterio de razones de mercado va con el ciclo económico; los

26 Kaufman, op. Cit., p. 635.

27 Entre los años 2000 y 2004, la tasa media anual de crecimiento del PIB fue $1.8 \%$, según el INEGI, Sistema de Cuentas Nacionales; la de crecimiento demográfico $1.3 \%$ y de la PEA, $2.0 \%$, según la Encuesta. 
de razones personales se sumaron por cierta comodidad estadística, pues estas razones no se aclaran en la Encuesta; su tasa sube en 1998 y baja después, como se ve en el Cuadro 7; pero la parte de desempleados por razones de mercado baja hasta el año 2000 y luego repunta, algo consistente con el rezago económico respecto al crecimiento de la PEA entre los años 2000 y 2004.

- Para la tasa de desempleo estructural (línea 7.3) se sumaron los que buscan trabajo por más de 14 semanas, los ocupados sin instrucción y los con primaria incompleta, tasa que sobrestimaría este desempleo porque no elimina la intersección de los tres grupos, mas la respectiva cifra no se publica; este desempleo se caracteriza por su larga duración y la falta de habilidades de los buscadores de trabajo respecto las exigidas en el mercado, de ahí que se hayan tomado las características señaladas. La tasa desciende pero se mantiene alta; la parte de los sin instrucción y de primaria incompleta desciende hasta el 2004, pero la desempleada por más de 14 semanas sólo hasta el 2000 , luego sube y se mantiene, algo también consistente con el crecimiento económico rezagado respecto al de la PEA.

Cuadro 7. Tasas por tipo de desempleo, 1996-2004 (\% PEA).

\begin{tabular}{|c|c|c|c|}
\hline & \multicolumn{3}{|c|}{ México } \\
\hline Año & Friccional & Cícliclo & Estructural1 \\
\hline 1996 & 3.0 & 8.6 & 29.5 \\
\hline 1998 & 2.0 & 12.5 & 27.4 \\
\hline 2000 & 1.5 & 12.1 & 25.8 \\
\hline 2002 & 1.7 & 9.5 & 24.4 \\
\hline 2004 & 1.6 & 9.0 & 21.8 \\
\hline
\end{tabular}

* Fuente: construido con datos del INEGI, según datos de la Encuesta Nacional de Empleo.

Como comentario final de esta sección cabe decir que al comparar las tasas de desempleo no se ven grandes diferencias en las friccionales, muy afectadas por el desempleo abierto; las del desempleo cíclico son mayores, lo que se explica porque la actividad productiva es sensible al mercado y éste a la evolución económica; la tasa de desempleo estructural registra una tendencia ligeramente descendente que dejaría entrever el decreciente impacto de factores estructurales, pero ésta es área que pide investigación porque sería la de más desempleo, y porque su causa básica es la inadecuación entre habilidades ofrecidas y requeridas y, así, cabe la siguiente cita:

En México la situación es contraria (respecto A Estados Unidos o Canadá), ya que los trabajadores con algún nivel de educación media o superior tienen tasas de desempleo más altas que los trabajadores con menos de seis años de educación. ${ }^{28}$

28 Acuerdo de Cooperación Laboral de América del Norte (ACLAN, 1997), Los mercados de trabajo en América del Norte, Secretaria of the Commission for Labor Cooperation, Dallas, TX, p. 56 . 
Algo decepcionante porque comparativamente a México le cuesta más el egreso de una persona del sistema educativo medio y superior, y luego no encuentra trabajo adecuado o no encuentra trabajo simplemente.

Otro modo de estimar los tipos de desempleo es con la curva de Beverdige, ${ }^{29}$ trazada en el sistema cartesiano donde el eje de abscisas mide el número de desempleados y el de ordenadas, el de vacantes; la referencia es la línea de $45^{\circ}$ que iguala desempleados y vacantes, o sea, pleno empleo según la tasa natural de desempleo, hoy NAIRU, ${ }^{30}$ que incluye al desempleo friccional; los puntos fuera de la línea de $45^{\circ}$ representan al desempleo cíclico; y Beveridge reconoce que no es fácil ubicar información de vacantes en Estados Unidos; para México tampoco se tiene esta cobertura, pero la Secretaría de Trabajo y Previsión Social (STPS) provee cifras de i) vacantes, ii) personas canalizadas a empleo y iii) número de personas que consiguen empleo (colocados); cifras de sondeo más que de muestreo; pero que acercan al problema desempleo. La información publicada en años anteriores y la de la página Internet de la STPS se incorpora al Cuadro 8.

Cuadro 8. Vacantes y personas canalizadas a empleo.

\begin{tabular}{|c|c|c|c|c|}
\hline Año & $\begin{array}{c}\text { Número de } \\
\text { Vacantes } \\
(1)\end{array}$ & $\begin{array}{c}\text { Canalizados } \\
\text { a Empleo } \\
(2)\end{array}$ & $\begin{array}{c}\text { No canalizados } \\
(3)=(1)-(2)\end{array}$ & $\begin{array}{c}\text { Colocados } \\
(4)\end{array}$ \\
\hline 1985 & 137,331 & 91,717 & 45,614 & $\mathrm{Nd}$ \\
\hline 1986 & 163,937 & 120,170 & 43,767 & $\mathrm{Nd}$ \\
\hline 1987 & 166,684 & 139,390 & 27,294 & $\mathrm{Nd}$ \\
\hline 1988 & 198,251 & 169,013 & 29,238 & $\mathrm{Nd}$ \\
\hline 1989 & 214,264 & 178,878 & 35,386 & $\mathrm{Nd}$ \\
\hline 1990 & 240,615 & 186,035 & 54,580 & $\mathrm{Nd}$ \\
\hline 1991 & 261,172 & 197,852 & 63,320 & $\mathrm{Nd}$ \\
\hline 1992 & 329,402 & 278,754 & 50,648 & $\mathrm{Nd}$ \\
\hline 1993 & 299,053 & 269,898 & 29,155 & $\mathrm{Nd}$ \\
\hline 2001 & 452,729 & 363,512 & 89,217 & 173,429 \\
\hline 2002 & 458,611 & 387,392 & 71,219 & 210,539 \\
\hline 2004 & 477,755 & 412,047 & 65,708 & 216,136 \\
\hline
\end{tabular}

* Fuente: hecho con datos de la Secretaría de Trabajo y Previsión Social (STPS).

$Y$ si se toma a los buscadores de empleo como desempleados y se confrontan con las vacantes, tal relación, según Beveridge, da el Gráfico 6, donde hay una correlación de 0.99 entre vacantes y desempleados; los puntos ubicados fuera de la línea de 450 serían de desempleo cŕclico; sin embargo, las cifras son las de canalizados a un empleo y esto no implica que todos lo ubiquen; es una primera aproximación, y al respecto la STPS dice que:

29 Bruce, Kaufman (1991). The economics of Labor Markets. The Dryden Press, U.S.A., pp. 622-626.

30 Tasa no aceleradora de inflación, por sus siglas en inglés: cuando el número de vacantes es igual al de desempleados. 
El total de personas canalizadas a un empleo es inferior a las vacantes registradas debido, principalmente a la falta de correspondencia entre las habilidades del trabajador y los requerimientos del puesto. Las personas canalizadas a un puesto vacante no son contratadas en su totalidad. ${ }^{31}$

Los porcentajes de no colocados y no canalizados respecto las vacantes son 62 , 54 y 55, para los años 2001, 2002 y 2004 respectivamente; según la cita de la STPS, el peso del desempleo estructural sería alto.

Gráfico 6. Hacia una curva de Beveridge.

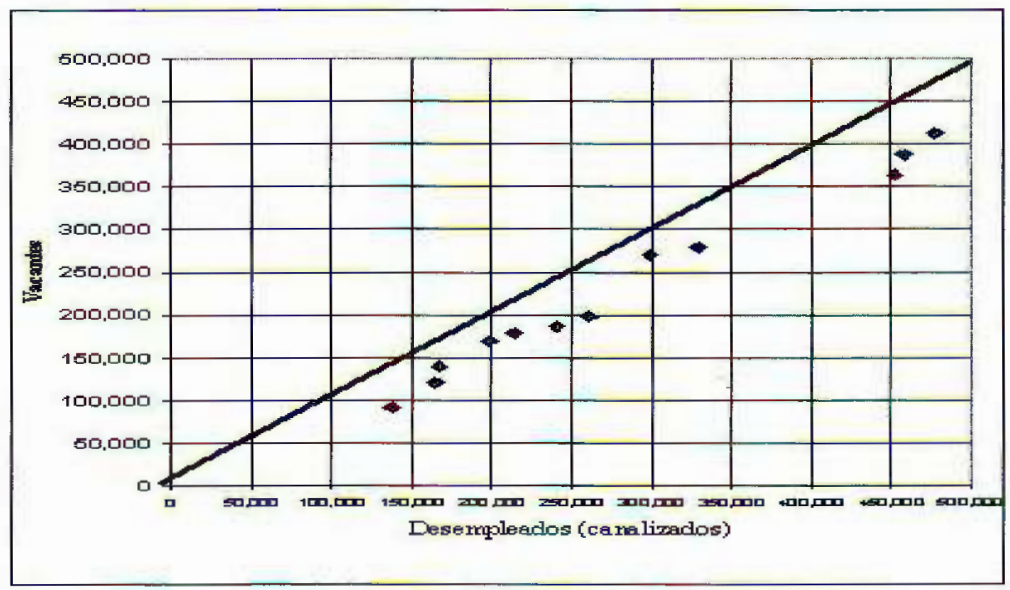

* Fuente: con datos de la STPS

\section{Perspectiva 2005-2015}

Luego de describir lo precario del empleo, se infiere que se debe procurar mejorar su calidad, hacerlo decente; pues más de 60 porciento es informal (Cuadro 1) y cerca del 40 se ubica sin pago, a destajo o por su cuenta, principalmente en las ramas agropecuaria, comercio y servicios personales. También urge una investigación acuciosa del empleo por ramas, pues se entrevé un dualismo, hay trabajadores asalariados, empleadores y por su cuenta con altos y bajos ingresos. ${ }^{32}$

A través de pruebas $\chi^{2}$ se advirtieron ${ }^{33}$ relaciones en las estructuras de ocupación según posición en el trabajo, ocupación principal y ramas de actividad económica, donde destaca que las ramas industriales (manufacturera, extractiva y electricidad), de servicios financieros, profesionales y sociales, $y$

31 INEGI (1994), Una visión de la modernización de México en cifras, Fondo de Cultura Económica, México, p.34.

32 Según La Encuesta, en el año 2004, 23.4\% de los ocupados laboraban 40 ó más horas por semana, pero recibían a lo sumo dos salarios mínimos (SM); $51.6 \%$ se ocupaba de 40 a 56 horas y $36 \%$ (con la misma base) percibía de uno a cinco SM. Y de los pocos que devengaban más de diez SM, la mayoría trabajaba al menos 40 horas.

33 Por razones de espacio, las pruebas $\chi^{2}$ no se muestran en el texto del trabajo. 
administración pública son las mejores opciones; convendría promoverlas para aumentar su ocupación, de asalariados principalmente.

El desempleo estructural sería alto, como se vio en los Cuadros 6 y 7, y en la Curva de Beverdige (Gráfico 6); resultando paradójico y preocupante que el desempleo sea alto en personas con niveles medios y altos de educación, según reporte de la comisión del trabajo para la zona del TLC; esto pide más investigación sobre la adecuación entre habilidades ofrecidas y requeridas. Para visualizar el futuro (des)empleo se proyectó la demanda laboral - empleo permanente o quizá decente - con los trabajadores permanentes inscritos en el IMSS en función del crecimiento económico y el salario real, en tres escenarios de tasa anual de crecimiento del PIB:

i) a la histórica de $2.85 \%$, ii) al $4.5 \%$, retadora pero viable; y iii) a $7 \%$, como escenario optimista. ${ }^{34}$ Se parte con datos del IMSS, que dan tendencia más que nivel del empleo porque omiten a los ocupados en Administración Pública y Defensa, y los del sistema educativo oficial, de empleos más bien estables, pero cuyos datos no se reportan con la frecuencia del IMSS, pero la subestimación no variaría mucho ${ }^{35}$ y así la tendencia estimada sería creíble; pero aun al procurar corregir tal subestimación, el empleo permanente resultaría muy inferior a la PEA. ${ }^{36}$

Las proyecciones se muestran en el Cuadro 9 donde demanda es el empleo permanente, pues creemos que no tiene sentido proyectar empleo sin considerar su calidad, mejorada en la ocupación formal o permanente, tendientes al empleo decente. En el cuadro se ve que de seguir la experiencia histórica, se ve una perspectiva pesimista pero realista, aun cuando las tasas de informalidad bajen al procurar obviar la subestimación del empleo permanente, pues el número de personas afectadas permanece alto; perspectiva traída al Gráfico 7 y similar por cierto al escenario pesimista del modelo de RyF, trazado en el Gráfico 2.

34 La proyección 2005-2015 de la PEA se hizo bajo la tendencia aparecida en la Encuesta, pero se ajustó a la del CONAPO, tomada de su página internet. La proyección de demanda laboral se basó en la función estadística obtenida de la encuesta según datos anules del periodo 1993-2004:

Demanda Laboral $=-3,590,011+13$ PIB $\$ 93-227,127.6$ Sal Min $\$ 93, \quad R^{2}=0.985$

Durbin Watson $=2.4$; error estándar de estimación $=292,244$; valores $t$ en ( ).

Cabe comentar que también se hicieron proyecciones de demanda laboral con una matriz de insumo-producto de 1990; los resultados son similares a los del Cuadro 9; pero no se presentan aquí porque tal matriz no es oficial y por razones de espacio.

35 Esta menor variación se entrevé porque según el INEGI, el total nacional de derechohabientes IMSS aumentó 11.9.\% entre los años 1996 y 2000; el de ISSSTE y otras instituciones públicas, 0.5\%; Ver INEGI (2001), Encuesta Nacional de Empleo y Seguridad Social 2000, Aguasaclientes, p. 9.

$36 \mathrm{El}$ empleo permanente se subestimaría así: el del IMSS es $78 \%$ del empleo permanente nacional; las otras fuentes (ISSSTE y otras instituciones públicas) no reportan datos periódicamente. El porcentaje $78 \%$ proviene de INEGI (2001), Encuesta Nacional de Empleo y Seguridad Social 2000. Aguascalientes, p.27. La subestimación procura salvar en las proyecciones a través de las cifras en las tres últimas líneas del Cuadro 9 , con base en el $78 \%$ citado. 
Gráfico 7. Oferta y demanda de trabajo en México, 1993-2015.

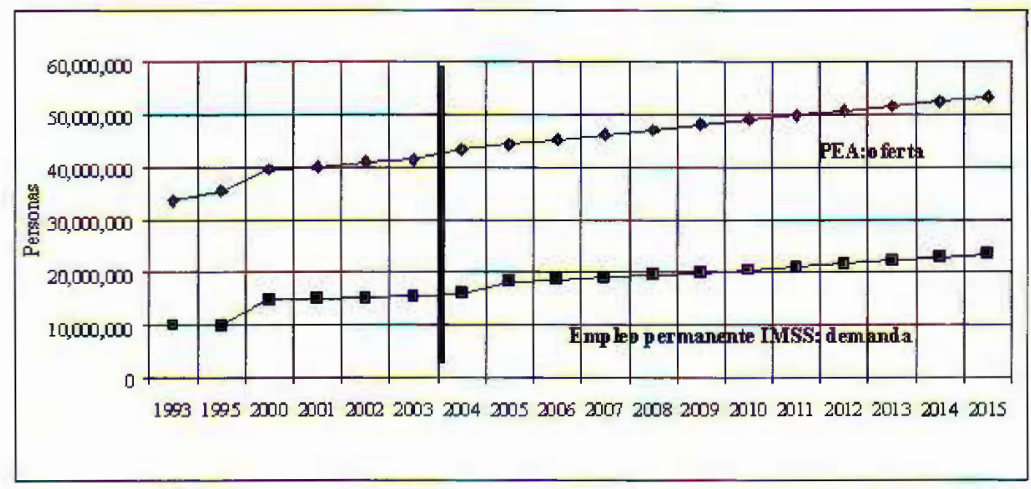

* Fuente: construido con datos de INEGI, Encuesta Nacional de Empleo; proyección PEA del CONAPO y la demanda, estimación propia.

Cuadro 9. Perspectiva laboral mexicana, 1993-2015.

\begin{tabular}{|c|c|c|c|c|}
\hline \multirow[b]{2}{*}{ AÑO } & \multirow{2}{*}{$\begin{array}{l}\text { Oferta } \\
\text { PEA }\end{array}$} & \multicolumn{3}{|c|}{$\begin{array}{c}\text { Empleo bajo tasas anuales del PIB, } \\
\text { sin cambio estructural }\end{array}$} \\
\hline & & $\begin{array}{c}\text { Histórica } \\
r_{p i b}= \\
2.85 \%\end{array}$ & $\begin{array}{c}r_{p i b}= \\
4.5 \%\end{array}$ & $\begin{array}{c}r_{p i b}= \\
7.0 \%\end{array}$ \\
\hline 1993 & $33,651,812$ & $10,033,167$ & - & - \\
\hline 1995 & $35,558,484$ & $10,005,109$ & - & - \\
\hline 2000 & $39,633,842$ & $14,859,221$ & - & - \\
\hline 2001 & $40,072,856$ & $15,017,813$ & - & - \\
\hline 2002 & $41,085,736$ & $15,170,468$ & - & - \\
\hline 2003 & $41,515,672$ & $15,479,349$ & - & - \\
\hline 2004 & $43,398,755$ & $\begin{array}{l}15,994,027 \\
64.0 \%\end{array}$ & - & - \\
\hline 2005 & $44,394,590$ & $\begin{array}{c}18,259,109 \\
58.9 \%\end{array}$ & $\begin{array}{c}18,552,036 \\
58.2 \%\end{array}$ & $\begin{array}{l}18,995,865 \\
57.2 \%\end{array}$ \\
\hline 2010 & $49,119,803$ & $\begin{array}{c}20,431,336 \\
58.4 \%\end{array}$ & $\begin{array}{l}22,123,648 \\
55.0 \%\end{array}$ & $\begin{array}{l}24,899,703 \\
49.3 \%\end{array}$ \\
\hline 2015 & $53,366,708$ & $\begin{array}{c}23,513,552 \\
55.9 \%\end{array}$ & $\begin{array}{c}27,570,090 \\
48.3 \%\end{array}$ & $\begin{array}{c}34,923,122 \\
34.6 \%\end{array}$ \\
\hline \multicolumn{5}{|c|}{$\%$ de PEA informal al eliminar la subestimación del empleo form } \\
\hline 2004 & - & $52.8 \%$ & - & - \\
\hline 2005 & - & $47.3 \%$ & $46.4 \%$ & $45.1 \%$ \\
\hline 2010 & - & $46.7 \%$ & $42.3 \%$ & $35.0 \%$ \\
\hline 2015 & - & $43.5 \%$ & $33.8 \%$ & $16.1 \%$ \\
\hline
\end{tabular}


Cuadro 9. (continuación).

\begin{tabular}{|c|c|c|c|c|}
\hline \multirow{2}{*}{} & \multirow{2}{*}{ Oferta } & \multicolumn{3}{|c|}{ Empleo bajo tasas anuales del PIB, } \\
& & Histórica & \multicolumn{2}{|c|}{ con cambio estructural* } \\
AÑNO & PEA & $r_{p i b}=$ & $r_{p i b}=$ & $r_{p i b}=$ \\
\hline 1993 & $33,651,812$ & $10,033,167$ & $4.5 \%$ & $7.0 \%$ \\
\hline 1995 & $35,558,484$ & $10,005,109$ & - & - \\
\hline 2000 & $39,633,842$ & $14,859,221$ & - & - \\
\hline 2001 & $40,072,856$ & $15,017,813$ & - & - \\
\hline 2002 & $41,085,736$ & $15,170,468$ & - & - \\
\hline 2003 & $41,515,672$ & $15,479,349$ & - & - \\
\hline 2004 & $43,398,755$ & $15,994,027$ & - & - \\
\hline & & $64.0 \%$ & & $18,995,865$ \\
\hline 2005 & $44,394,590$ & $18,259,109$ & $18,552,036$ & $57.2 \%$ \\
\hline 2010 & $49,119,803$ & $20,589,992$ & $22,295,445$ & $25,093,058$ \\
& & $58.1 \%$ & $54.6 \%$ & $48.9 \%$ \\
\hline 2015 & $53,366,708$ & $23,878,733$ & $27,998,272$ & $35,465,501$ \\
& & $55.3 \%$ & $47.5 \%$ & $33.5 \%$ \\
\hline$\%$ de PEA informal al eliminar la subestimación del empleo formal \\
\hline 2004 & - & 52.8 & - & - \\
\hline 2005 & - & $47.3 \%$ & $46.4 \%$ & $45.1 \%$ \\
\hline 2010 & - & $46.3 \%$ & $41.8 \%$ & $34.5 \%$ \\
\hline 2015 & - & $42.6 \%$ & $32.7 \%$ & $14.8 \%$ \\
\hline
\end{tabular}

* Cambio estructural implica reducir el peso del PIB en los sectores comercio y servicios personales en $3 \%$ cada uno, y pasarlos a los de agricultura (1.5\%), manufactura (3\%) y construcción (1.5\%). Fuente: Los datos de la PEA de 1993 a 2004 son del INEGI, Encuesta Nacional de Empleo; la demanda de trabajo histórica son del empleo permanente según el IMSS. Nota: Las cifras en porcentajes de PEA informal: por ejemplo, la cifra histórica del 2004 se obtuvo así: (PEA-PEA formal) / PEA $=(43,398,755-15,994,027)$ $\mathrm{x} 100 / 43,398,755=64.0$ porcentaje.

Cabe insistir en que las proyecciones del Cuadro 9 implican tasas de crecimiento del PIB sostenidas para que la formalidad crezca; un factor coadyuvante al empleo es que la PEA estaría reduciendo su tasa de crecimiento, cuyo máximo se daría ahora, en el lustro 2000-2005, luego decrecería porque: i) se dejará sentir el efecto rezagado de la menor fecundidad promovida desde los años setenta, y ii) a que mucha cantera femenina ya se incorporó a la oferta laboral, y a futuro disminuiría su tasa de incorporación. ${ }^{37}$

37 Recuérdese que la proyección de la PEA se basa en la del CONAPO. 


\section{Los requerimientos financieros}

Pero debe recordarse, que ni la técnica, ni por supuesto el ahorro, garantizan una elevación de la renta. Lo que hacen es colocar en nuestras manos el poder y la capacidad de lograr una renta creciente. Evsey D. domar

A menudo la escasez de capital limita el proceso de desarrollo económico, es cuello de botella, así que gobernantes y empresarios buscan atraer inversión; pero cabe preguntar:

1) ¿Qué inversión se necesita para que la economía crezca a las tasas aquí sugeridas?

2) ¿Cuánto cuesta crear un empleo?

3) ¿Cuánto invertir para crear los empleos requeridos en el horizonte 20052015 , según las proyecciones aquí presentadas?

4) ¿Cómo la inversión cambia en los escenarios señalados en el Cuadro 9 ?

Preguntas cuyas respuestas ahora se ensayan por asociar el empleo a metas de crecimiento medidas por el producto interno bruto per capita $\left(P I B_{p c}\right)$; para ello se estiman: 1) los requerimientos del ahorro nacional bajo los escenarios de crecimiento del PIB referidos en el Cuadro 11; y 2) ligar esos requerimientos al empleo formal para coadyuvar a reducir la informalidad laboral.

\section{1 ¿Qué inversión se precisa para que la economía crezca?}

Para estimar el cambio en el producto interno bruto per capita, $P I B_{p c}$, cabe relacionar su tasa de crecimiento $(y)$ respecto a: i) la parte que del PIB se ahorra, o tasa de ahorro $(S)$, ii) la razón capital/producto $(k)$, y iii) el crecimiento demográfico $(r)$; lo que aquí se hace con el viejo modelo HarrodDomar, ${ }^{38}$

$$
y=(S / k)-r
$$

Así, para que el $P I B_{p c}(y)$ crezca, debe subir la tasa de ahorro $(S)$, bajar la razón capital/producto $(k), \mathrm{y} / \mathrm{o}$ reducir la tasa de crecimiento demográfico. La expresión (1) puede presentarse así:

$$
S=k(y+r)
$$

Que se aplicó a México para el periodo $1980-2000$ y se comparan los resultados obtenidos con los parámetros de Naciones Unidas, con experiencias de muchos países; la tasa de ahorro histórica en México según la fórmula (2) sería 10.9\%, como se ve en el Cuadro 10.

38 Son dos referencias: i) Domar, E., Expansion and employment, American Economic Review, March 1947, pp. 34-55; ii) R. F.Harrod, Domar and Dynamics Economics, The Economic Journal, vol. 69, September 1959, pp. 451-464. 
Cuadro 10. Aplicación de la función de Harrod-Domard a México entre 1980-2000 y su comparación con tablas de Naciones Unidas.

\begin{tabular}{|c|c|c|}
\hline Concepto & Tablas de N.U. & En México \\
\hline Tasa de crecimiento demográfico & 2.0 & 1.9 \\
\hline Tasa de aumento del PIB per capita & 1.0 & 1.0 \\
\hline Razón inversión/producto & 3.5 & 3.7 \\
\hline Tasa de ahorro,\% de PIB & 10.5 & 10.9 \\
\hline
\end{tabular}

* Fuente: datos de Naciones Unidas, Factores Determinantes y Consecuencias de las Tendencias Demográficas, ONU, Nueva. York, 1978, p. 476. Para México las tasas de crecimiento demográfico y del PIBpc se estimaron con base en los censos de población y del Sistema de Cuentas Nacionales; la tasa de inversión neta, de los reportes 1980-2000 de CIEMEX-WEFA. Las dos columnas implican una ecuación de primer grado, cuya incógnita se marca en negrita, pues se conocen los otros tres componentes.

Estimación que ayuda a proyectar el ahorro requerido bajo diferentes escenarios, para ubicar la tendencia que genere más empleo. Vale anotar que el modelo Harrod - Domar se usó porque:

Se pueden demostrar los efectos del crecimiento de la población en la inversión mediante un modelo simplificado de una economía, basado en el análisis del proceso del crecimiento económico ideado por Harrod y Domar. Naciones Unidas (1978), Factores determinantes y consecuencias de las tendencias demográficas. Volumen I. Nueva York, nota 199, [1978: 474].

$\mathrm{Y}$ aunque no siempre la razón media (capital/producto $=\mathrm{K} / \mathrm{L}$ ) es igual a la razón marginal $(\Delta K / \Delta L)$, no se descarta esa posibilidad:

Debe hacerse una distinción entre la relación capital-producción marginal y la media, siendo esta última la cantidad de capital necesaria para la producción de una unidad como promedio, en tanto que la primera relaciona las adiciones netas de capital o de inversión con el correspondiente aumento de la producción. Si bien es posible que ambas relaciones sean iguales, no lo son necesariamente.

El modelo toma la inversión neta, descuenta depreciación; la razón inversiónproducto 3.7 para México es nuestro resultado e indica que se necesita invertir $3.7 \%$ del PIB para que éste crezca 1\%, dado el crecimiento poblacional de $1.9 \%$ y la tasa de inversión neta de 10.9. Ahora se hace a la tasa de crecimiento del $P I B_{p c}$ meta de tres escenarios: $0.85 \%, 2.5 \%$ y $5 \%$ anual, o sea, el PIB debería crecer como en $2.85 \%, 4.5 \%$ y $7 \%$ (suponiendo una tasa anual de $2 \%$ de crecimiento poblacional).

La inversión neta histórica de $10.9 \%$ mexicana no parece haber cumplido bien su papel para absorber a la nueva fuerza de trabajo, así que el PIB per 
capita creció sólo $1.0 \%$ anual entre los años 1980 y $2000 ;^{39}$ insuficiencia que explica el creciente número de ocupados informales.

\section{2 ¿Cuánto invertir para crear un empleo?}

Para esto se usó la información del censo económico del 2000, con datos de 1998 , como se ve en el Cuadro 11, donde la inversión por empleo promedia casi 18,000 dólares de 1998, y se ubica en parámetros internacionales. ${ }^{40} \mathrm{Y}$ si bien la razón capital/trabajador media es 178,300 pesos de $1998,{ }^{41}$ implica alta varianza (el rango va de 36.3 miles de pesos en transporte en autos de alquiler a $3,841.4$ de la industria eléctrica) que exige cautela al analizar las ramas trabajo intensivas, las de menor razón capital/producto, si se busca acrecentar el empleo.

\section{3 ¿Cuánto invertir para crear los empleos requeridos anualmente?}

La inversión requerida por empleo es parte de la inversión total que promueve el crecimiento económico, pues aunque la razón capital/trabajo implica capital fijo directo (maquinaria, equipo, edificios y terrenos), ${ }^{42}$ el ahorro nacional va a otras inversiones también, como infraestructura. Así que sólo por crecer el PIB a la tasa de $7 \%$ anual sostenida, la demanda de fuerza de trabajo sería la meta de empleos menos lejana a los requeridos; de no crecer la economía así, se dejará crecer a la informalidad, y sería mayor al 40.1 porciento de la PEA actual, como señala la OIT. ${ }^{43}$ La comparación de las proporciones del PIB de inversión total y su componente empleo se presenta en el Cuadro 12, donde la parte de la inversión para empleo se presentan bajo los encabezados de porcentajes de inversión total (según el modelo Harrod-Domar) para lograr las metas de crecimiento del $P I B_{p c}$, y se ve que las tasas de crecimiento de éste, aun modestas, implican una tasa de inversión neta mayor a la histórica 10.9\%; entonces se precisa de un gran esfuerzo para aumentarla, lo que corresponde al sector empresarial principalmente. Cabe recalcar las tendencias que se mostraron en el Cuadro 11, donde se ve qué difícil es cubrir un millón de empleos formales al año y prácticamente imposible absorber también 23 millones de trabajadores informales del año 2004; lo primero implica subir la tasa de inversión del 10.9\% histórico al $21.0 \%$ del PIB, para que el PIB creciese al $7 \%$ anual, ${ }^{44}$ como ve en el Cuadro 12.

39 Duplicar el PIB per capita con esta tasa, llevaría 70 años.

40 Presentados por Husted, Steve y Melvin, Michael (1995), International Economics. Harper Collins, New York, p. 93. O por Salvatore, Dominick (1999), Economía Internacional, Prentice Hall, México, p. 195.

41 El dato de capital/trabajo del censo de 1995 (con datos de 1993) era de 22,450 dólares, grosso modo, porque las ramas económicas eran menos detalladas.

42 Se tomó como capital a los activos fijos netos, o sea, todos aquéllos bienes muebles e inmuebles que tienen capacidad de producir o que coadyuvan a la producción de bienes y servicios. Ver INEGI (2000) Censos económicos 1999 (Glosario).

43 Página de internet de la OIT.

44 Según recomendación de The World Bank (2001), Mexico. A Comprehensive Development Agenda for the New Era, Washington, .D. C, p. 31. 
Cuadro 11. Estimación de las razones capital/trabajador y capital/producto, en pesos de 1998.

\begin{tabular}{|c|c|c|c|}
\hline Rama de actividad & $\begin{array}{c}\text { Activos Fijos } \\
\text { Netos } \\
\text { Mile } \$ \text { de } 1998 \\
1\end{array}$ & $\begin{array}{c}\text { Ocupación } \\
2\end{array}$ & $\begin{array}{c}K / L \\
(3)=(1) /(2)\end{array}$ \\
\hline Pesca & $8,021,070$ & 154,379 & 52 \\
\hline $\begin{array}{c}\text { Minería y extracción } \\
\text { de Petróleo }\end{array}$ & $184,148,279$ & 108,810 & $1,692.40$ \\
\hline Construcción & $29,552,227$ & 620,997 & 47.6 \\
\hline Industria eléctrica & $413,913,509$ & 107,751 & $3,841.40$ \\
\hline $\begin{array}{c}\text { Captación, tratamiento y } \\
\text { distribución de agua }\end{array}$ & $47,358,748$ & 80,888 & 585.5 \\
\hline Industria de alimentos & $148,624,306$ & 791,297 & 187.8 \\
\hline Industria textil & $62,073,892$ & 894,005 & 69.4 \\
\hline Industria de la madera & $12,676,614$ & 213,998 & 59.2 \\
\hline Industria de papel & $63,606,766$ & 222,609 & 285.7 \\
\hline Productos químicos & $238,548,170$ & 479,855 & 497.1 \\
\hline Minería no metálica & $80,578,567$ & 200,643 & 401.6 \\
\hline Industria metálica básica & $80,908,255$ & 44,981 & $1,798.70$ \\
\hline Productos metálicos & $196,642,498$ & $1,318,808$ & 149.1 \\
\hline Otras manufacturas & $3,896,850$ & 66,126 & 58.9 \\
\hline Comercio & $195,133,986$ & $3,784,869$ & 51.6 \\
\hline Transporte eléctrico. & $37,770,659$ & 18,845 & $2,004.30$ \\
\hline Transporte de carga & $29,632,922$ & 171,380 & 172.9 \\
\hline Transporte de pasajeros & $27,774,997$ & 177,767 & 156.2 \\
\hline $\begin{array}{l}\text { Transporte en autos } \\
\text { de alquiler }\end{array}$ & $9,253,815$ & 255,251 & 36.3 \\
\hline Transporte por agua & $14,079,923$ & 15,544 & 905.8 \\
\hline Comunicaciones & $123,466,622$ & 132,770 & 929.9 \\
\hline Servicios & $450,121,146$ & $3,920,600$ & 114.8 \\
\hline Total & $2,457,783,821$ & $13,782,173$ & 178.3 \\
\hline \multicolumn{3}{|c|}{ Tipo de cambio, pesos por dólar en 1998} & 9.91 \\
\hline \multicolumn{3}{|c|}{ Razón media capital/producto en dólares } & 17,995 \\
\hline
\end{tabular}


Cuadro 11 (continuación).

\begin{tabular}{|c|c|c|}
\hline Rama de actividad & $\begin{array}{c}\text { Valor Agregado } \\
\text { censal bruto } \\
\text { Mile } \$ \text { de } 1998 \\
4\end{array}$ & $\begin{array}{c}\mathrm{K} / \mathrm{PIB} \\
(5)=(1) /(4)\end{array}$ \\
\hline Pesca & $5,839,137$ & 1.37 \\
\hline $\begin{array}{c}\text { Minería y Extracción } \\
\text { de Petróleo }\end{array}$ & $132,714,645$ & 1.39 \\
\hline Construcción & $31,893,013$ & 0.93 \\
\hline Industria eléctrica & $52,319,77 \overline{4}$ & 7.91 \\
\hline $\begin{array}{l}\text { Captación, tratamiento } \\
\text { y distribución de agua }\end{array}$ & 0 & - \\
\hline Industria de alimentos & $121,563,141$ & 1.22 \\
\hline Industria textil & $49,478,632$ & 1.25 \\
\hline Industria de la madera & $10,268,257$ & 1.23 \\
\hline Industria de papel & $30,431,088$ & 2.09 \\
\hline Productos químicos & $112,727,329$ & 2.12 \\
\hline Minería no metálica & $35,424,266$ & 2.27 \\
\hline Industria metálica básica & $29,007,453$ & 2.79 \\
\hline Productos metálicos & $187,683,019$ & 1.05 \\
\hline Otras manufacturas & $4,529,820$ & 0.86 \\
\hline Comercio & $351,257,743$ & 0.56 \\
\hline Transporte eléctrico. & $118,677,557$ & 0.32 \\
\hline Transporte de carga & 0 & - \\
\hline Transporte de pasajeros & 0 & - \\
\hline $\begin{array}{c}\text { Transporte en autos } \\
\text { de alquiler }\end{array}$ & 0 & - \\
\hline Transporte por agua & 0 & - \\
\hline Comunicaciones & 0 & - \\
\hline Servicios & $280,954,364$ & 1.60 \\
\hline Total & $1,554,769,238$ & 1.58 \\
\hline \multicolumn{2}{|c|}{ Tipo de cambio, pesos por dólar en 1998} & 9.91 \\
\hline \multicolumn{2}{|c|}{ Razón media capital/producto en dólares } & 17,995 \\
\hline
\end{tabular}

* Fuente: construido con datos de los censos económicos de 2000 (con datos de 1998). 
Cuadro 12. Inversión anual para generar empleos anualmente.

\begin{tabular}{|c|c|c|c|}
\hline Periodo & $2005-2010$ & $2010-2015$ & Escenarios \\
\hline Creciendo el PIB al 2.85\% anual precisa una inversión de $8.55 \%$ del PIB \\
\hline Inversión fija como \% PIB & 2.85 & 3.56 & Extrapolativo \\
& 3.00 & 3.75 & Restructurado \\
\hline \multicolumn{4}{|c|}{ Creciendo el PIB al 4.5\% anual precisa una inversión de $13.5 \%$ del PIB } \\
\hline Inversión fija como\% PIB & 4.45 & 5.60 & Extrapolativo \\
& 4.60 & 5.75 & Restructurado \\
\hline Creciendo el PIB al 7.0\% anual precisa una inversión de 21.0\% del PIB \\
\hline Inversión fija como \% PIB & 6.85 & 8.50 & Extrapolativo \\
& 7.00 & 8.75 & Restructurado \\
\hline
\end{tabular}

* Fuente: Estimación propia mediante el cociente de la multiplicación inversión por empleo por el número de trabajadores, sobre el PIB proyectado. Se supuso la razón capital $/$ producto $=3$; si el PIB creciese $2.85 \%$, la inversión requerida sería $2.85 \times 3=$ $8.55 \%$.

Cabe recordar que al estimar la tasa de ahorro con el modelo Harrod-Domar se usó la razón capital/producto 3 para requerimientos de inversión por empleo, las de inversión por empleo, de 18,000 dólares de 1998, ambos estimadores dentro de rangos aceptables bajo comparaciones internacionales; el primero en tablas de Naciones Unidas, da $10.5 \%$ para las respectivas tasas de crecimientos de $2.0 \%$ y $1.0 \%$ demográfica y del $P I B_{p c} ;$ el scgundo de 18,000 dólares de 1998 , en el rango que presentan Husted-Melvin o Salvatore. ${ }^{45}$

\section{Conclusiones}

- Los empleos requeridos en el horizonte trazado son como de un millón por año, sólo para la nueva PEA (Cuadro 9); perspectiva que reta a los tomadores de decisiones (políticos, empresario e intelectuales principalmente); en el mejor de los casos -que la economía creciese sostenidamente $7 \%$ anual- la informalidad se reduce, pero queda lejos de ser abatida: de $64 \%$ a $33.5 \%$ entre los años 2004 y 2015, Cuadro 9, donde empleo informal es el de sin prestaciones, que alimenta el llamado desempleo estructural (Cuadros 6 y 7, Gráfico 6).

- Si la economía creciese más rápido de lo que la historia ha mostrado, se precisa una tasa de ahorro mucho mayor que la registrada, que pasaría de $8.55 \%$ a $21 \%$ del PIB para fomentar la inversión que promueva el empleo permanente o decente: de $2.85 \%$ a $7 \%$ del PIB (Cuadro 12). De otro modo, el empleo iría como lo señalan $\mathrm{RyF}$ en su trazo pesimista, como se evidencia al comparar los Gráficos 2 y 7.

- Y aunque el crecimiento económico y la inversión no sean suficientes para promover el crecimiento y el empleo requeridos, sí son necesarios.

- Para una mejor visión de la perspectiva, se estimaron los montos financieros requeridos que de no satisfacerse, se promovería que el (des)empleo

45 Estimando un $2 \%$ anual de alza en precios de los Estados Unidos queda $13,700 \times 1.02^{13}$ $=17,700$ dólares, porque estos autores dan la razón capital/trabajador en precios de 1985 . 
informal continúe creciendo. Así, un puesto de trabajo costaba 18 mil dólares de 1998 y la relación capital/PIB aproximaba 3.5 (Cuadro 10); y la del sector quizá formal, emanada del censo económico con datos de 1998, era como de 1.6 (Cuadro 11); diferencia en principio atribuible a la infraestructura y el valor de tierras agropecuarias; diferencia que reclama una investigación que por ahora se sale de nuestro objetivo; pero seguramente esas razones deben modificarse por el avance tecnológico y eso nos haría más opltimistas (menos pesimistas) en las proyecciones aquí presentadas.

Finalmente, cabe recordar que hay otros aspectos que impactan el empleo (tecnología, educación, capacitación) que requieren de investigación; aquí sólo se planteó el problema de la perspectiva laboral, que es la pauta de planeación y políticas; y es recomendable darle seguimiento, pues los buscadores de trabajo viven actualmente y lo buscarán en los próximos años, incluso más allá del horizonte aquí trazado; de otro modo, no esperemos un futuro muy halagüeño.

\section{Bibliografía}

Consejo Nacional de Población, CONAPO (2000). Proyecciones de la Población Económicamente Activa, de la matrícula educativa, de los hogares y las viviendas y de la población por tamaño de la localidad. México.D. F.

Domar, E. (March, 1947). Expansion and employment. American Economic Review.

Husted, S. and M. Melvin (1995). International Economics. New York: Harper Collins.

Instituto Nacional de Estadística, Geografía e Informática, INEGI. Sistema de Cuentas Nacionales de México. Aguascalientes, varios años.

INEGI (1995). XIV Censo Industrial, XI Censo Comercial y XI Censo de Servicios. Censos Económicos. Aguascalientes, México: INEGI.

INEGI (1999). Censos Económicos. Aguascalientes, México: INEGI.

INEGI (1999). Industria maquiladora de exportación. Aguascalientes, México: INEGI.

INEGI (2001). Estados Unidos Mexicanos . XII Censo general de Población y Vivienda 2000. Aguascalientes, México: INEGI.

INEGI-STPS, Secretaría del Trabajo y Previsión Social (1993-2003). Encuesta Nacional de Empleo. Aguascalientes, México: INEGI.

INEGI (2004), Encuesta Nacional de Empleo, de 1993 a 2004, Aguascalientes.

Jones, C. (2000). Introducción al crecimiento económico, Prentice Hall, México.

Lewis, A. (1963). Desarrollo económico con oferta ilimitada de trabajo. En Agarwala y Singh (eds.). La economía del subdesarrollo. Madrid: Tecnos, pp. 333-374.

Matriz de insumo producto 1990. Diskette conseguido en forma particular.

Méndez, Villarreal S.(14 de mayo 1975). Urgen 800 mil nuevos empleos. Revista Siempre, p. 19.

Méndez, Villarreal S.(19 de mayo de 1975). Medio, no fin crear empleos. Revista Siempre, p. 19 .

Méndez, Villarreal S. (5 de noviembre de 1975). Inflación y desempleo. La recuperación. Revista Siempre, p. 14.

Méndez, Villarreal S. (1976). La relación capital - producto en la economía mexicana. México, D.F.: El Colegio de México.

Naciones Unidas (1978). Factores determinantes y consecuencias de las tendencias demográficas. Volumen I. Nueva York: ONU.

Ranis, G. and J. Fei (1961). A theory of economic development. American Economic Review, pp. $533-565$.

Salvatore, D. (1999). Economía Internacional . México, D.F.: Prentice Hall. 